\title{
Does MOG Ig-positive AQP4-seronegative opticospinal inflammatory disease justify a diagnosis of NMO spectrum disorder? OPEN
}

Scott S. Zamvil, MD,

$\mathrm{PhD}$

Anthony J. Slavin, $\mathrm{PhD}$

Correspondence to

Dr. Zamvil:

zamvil@ucsf.neuroimmunol.org

\section{ABSTRACT}

While neuromyelitis optica (NMO) immunoglobulin (lg) $\mathrm{G}$ is considered the hallmark serologic marker of NMO, its association is not absolute, as NMO IgG is not detected in approximately one-fourth of the patients diagnosed with NMO spectrum disorder (NMOSD). Thus, the recent discovery that antibodies to myelin oligodendrocyte glycoprotein (MOG) are detected in some NMO IgG-seronegative patients manifesting clinical and neuroimaging signs of NMO or NMOSD has created tremendous excitement. However, it may be premature to classify this subgroup as NMOSD. NMO is considered an autoimmune astrocytopathy, and aquaporin-4 (AQP4), expressed on astrocytes, is recognized as the target autoantigen of $\mathrm{NMO} \mathrm{lgG}$. As its name denotes, MOG is produced by oligodendrocytes, CNS myelin-producing cells, and MOG is well-recognized as one of the candidate autoantigens in multiple sclerosis (MS) and acute disseminated encephalomyelitis (ADEM). Thus, is it possible that the clinical NMOSD-like phenotype associated with MOGspecific antibodies represents a variant of opticospinal MS or ADEM but not AQP4 autoimmunity or NMOSD? Whether this MOG-Ig positive AQP4-seronegative phenotype should be classified as NMOSD, opticospinal MS, or a unique entity is not simply a theoretical question but rather has practical implications for patients, their physicians, insurance carriers, and clinical investigators conducting NMO treatment trials. Neurol Neuroimmunol Neuroinflamm 2015;2:e62; doi: 10.1212/ NXI.0000000000000062

\section{GLOSSARY}

ADEM = acute disseminated encephalomyelitis; $A Q P 4=$ aquaporin-4; EAE = experimental autoimmune encephalomyelitis; GFAP = glial fibrillary acidic protein; HLA = human leukocyte antigen; $\mathbf{l g}=$ immunoglobulin; $\mathbf{M B P}=$ myelin basic protein; MHC = major histocompatibility complex; $\mathbf{M O G}=$ myelin oligodendrocyte glycoprotein; $\mathbf{M S}=$ multiple sclerosis; $\mathbf{N M O}=$ neuromyelitis optica; NMOSD = NMO spectrum disorder; OB = oligoclonal lgG band

Despite the use of sensitive assays, aquaporin-4 (AQP4)-specific antibodies are not detected in $10 \%-40 \%$ of patients diagnosed with neuromyelitis optica (NMO) or NMO spectrum disorder (NMOSD). ${ }^{1}$ It is also recognized that AQP4 immunoglobulin (Ig) $\mathrm{G}^{+} \mathrm{NMO}$ patients frequently produce other autoantibodies, including antibodies that target nuclear and cytoplasmic antigens identified in certain systemic rheumatologic diseases, including systemic lupus erythematosus and Sjögren syndrome. ${ }^{2}$ Together, these observations raise the possibility that antibodies in some patients with NMO or NMOSD might also target another CNS autoantigen(s). In this regard, anti-myelin oligodendrocyte glycoprotein (MOG) antibodies (MOG $\mathrm{Ig}^{+}$) have been identified in some patients diagnosed with NMO or NMOSD. ${ }^{3-8}$ When 3 separate groups evaluated antibodies to both MOG and AQP4 in patients with NMOSD, ${ }^{3,4,8}$ they observed that NMO IgG was only rarely detectable in MOG $\mathrm{Ig}^{+}$patients, and conversely, anti-MOG Ig was not observed in nearly all NMO IgG-seropositive NMO patients. Thus, excluding potential issues regarding the sensitivity of the assays, reactivity to these CNS autoantigens was essentially mutually exclusive. Despite differences in ethnicity in the patient populations studied, these 3 investigations identified similar clinical features in this MOG

\footnotetext{
From the Department of Neurology and Program in Immunology (S.S.Z.), University of California, San Francisco; and Abbvie Bioresearch Center Inc. (A.J.S.), Worcester, MA.

Go to Neurology.org/nn for full disclosures. Funding information and disclosures deemed relevant by the authors, if any, are provided at the end of the article. The Article Processing Charge was paid by the authors.

This is an open access article distributed under the terms of the Creative Commons Attribution-Noncommercial No Derivative 3.0 License, which permits downloading and sharing the work provided it is properly cited. The work cannot be changed in any way or used commercially.
} 
$\mathrm{Ig}^{+}$patient subpopulation, including a higher proportion of males, fewer relapses, and better recovery than AQP4-seropositive NMO. MOG $\mathrm{Ig}^{+}$AQP4-seronegative opticospinal disease therefore manifests with clinical features that are distinct from classical AQP4seropositive NMO.

From a clinical perspective, there are compelling reasons to include this $\mathrm{MOG} \mathrm{Ig}^{+}$subgroup of patients under the umbrella of NMOSD. Physicians and their patients rely on appropriate diagnosis when initiating therapeutic intervention. As AQP4-specific antibodies cannot be demonstrated in some individuals suspected of having NMO, identification of subgroups of AQP4-seronegative patients that produce antibodies to other target CNS autoantigens could facilitate its diagnosis. Optic nerves and spinal cord, the 2 anatomic sites affected most frequently in NMO, are not safely accessible for biopsy. Thus, diagnosis of NMO or NMOSD is ideally based on clinical manifestations, neuroimaging, and serology. Lastly, a diagnosis of NMOSD may be advantageous when patients are attempting to secure insurance coverage for costly NMO treatments. Nevertheless, there may be other clinical concerns in applying the term MOG $\mathrm{Ig}^{+}$AQP4-seronegative NMO. For example, interferon $\beta$ and natalizumab, 2 medications approved for treatment of multiple sclerosis (MS), may exacerbate AQP4-seropositive NMO. ${ }^{9-12}$ One can imagine that treatment decisions may become more complex if the pathology of this MOG $\mathrm{Ig}^{+}$ opticospinal inflammatory condition is different from AQP4-seropositive NMOSD.

The limited knowledge of the mechanisms responsible for the pathogenesis further highlights the issues in currently applying the term NMOSD to MOG $\mathrm{Ig}^{+}$opticospinal inflammatory disorder. Serum antibodies against MOG are most well-recognized in acute disseminated encephalomyelitis (ADEM), ${ }^{13}$ especially in pediatric patients, ${ }^{13-19}$ and have now been identified in children diagnosed with $\mathrm{NMO}^{7}$ or with clinical presentations resembling NMO, i.e., longitudinally extensive transverse myelitis ${ }^{19}$ or recurrent optic neuritis. ${ }^{18}$ The immunology, pathology, and genetics of MOG Ig-associated opticospinal disease and NMOSD might be quite distinct. Since the discovery of NMO IgG in 2004, ${ }^{20}$ the presence of these antibodies in patients has provided diagnostic confirmation and served to distinguish NMO from MS or other forms of CNS demyelinating disease. ${ }^{21}$ AQP4, the most abundant CNS water channel protein, is highly expressed on astrocyte foot processes at the blood-brain barrier, ${ }^{22}$ and pathologic studies of NMO lesions demonstrate injury to astrocytes associated with deposition of Ig and complement, providing further support for a humoral immune pathogenesis (see the figure). In contrast to MS, in NMO there is relative sparing of myelin, considered the primary immune target in MS. The presence of antibodies is a hallmark feature of type $2 \mathrm{MS}$ pathologic lesions. ${ }^{23}$ Furthermore, anti-MOG antibodies have been identified in MS lesions, in particular those associated with vesicular demyelination. ${ }^{24}$ The MOG $\mathrm{Ig}^{+}$NMOSDlike clinical phenotype might therefore represent an opticospinal type 2 MS variant. Whereas lymphocytes are characteristic of newly forming MS lesions, ${ }^{25}$ the cellular composition of NMO lesions is marked by the presence of neutrophils and eosinophils, ${ }^{22} 2$ leukocyte subtypes not normally detected in MS. Of interest, mice containing T cells specific for MOG develop optic neuritis, ${ }^{26}$ and when both $\mathrm{T}$ cells and B cells target MOG, they spontaneously develop an opticospinal form of experimental autoimmune encephalomyelitis (EAE) that is characterized by lymphocytic infiltrates. ${ }^{27-29}$ It should also be beneficial to determine whether there are genetic associations with this unique phenotype. MS is associated with human leukocyte antigen (HLA)-DR2 (DRB1*1501), and NMO has been associated with HLA-DR17 (DRB1*0301). ${ }^{30}$ Antibody responses may be associated with HLA subtypes (i.e., major histocompatibility complex [MHC] restriction). Although serum anti-MOG antibodies are not a characteristic feature of $\mathrm{MS}^{31}$ and data indicate anti-MOG antibodies in pediatric ADEM are not related to specific MHC II (i.e., HLA-D) genes, ${ }^{32}$ it is important to determine whether MOG $\mathrm{Ig}^{+}$AQP4-seronegative opticospinal inflammatory disease is associated with either HLA-DR2 or HLA-DR17. 


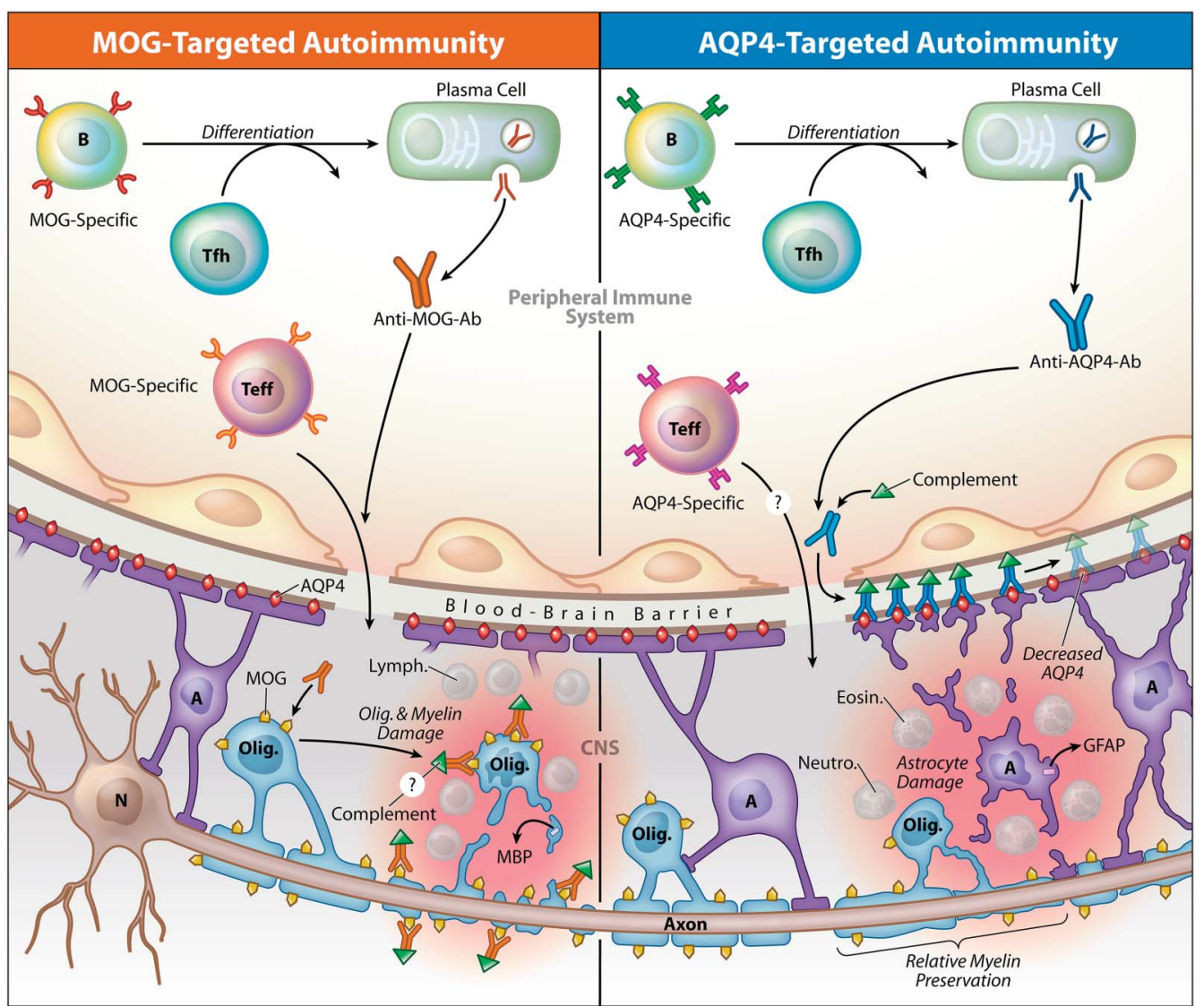

MOG-specific and AQP4-specific antibodies (Ab) target 2 different CNS resident cell populations, the oligodendrocyte (Olig.) or the astrocyte (A), respectively. Data indicate that antibodies are produced outside the CNS in both MOG $\mathrm{Ig}^{+}$ AQP4-seronegative opticospinal inflammatory disease (left) and AQP4-seropositive neuromyelitis optica spectrum disease (NMOSD) (right). AQP4-specific antibodies are IgG1, an antibody subclass that requires assistance from antigen-specific $T$ follicular helper (Tfh) cells when B cells differentiate into plasma cells. ${ }^{49}$ Anti-MOG antibodies appear as IgG in the diagram, although the antibody isotype is currently unknown. Serum antibodies to either MOG or AQP4 alone are not considered pathogenic in the absence of a cell-mediated inflammatory response. MOG-specific T effector cells (Teff), like in experimental autoimmune encephalitis (EAE) ${ }^{50}$ and possibly in multiple sclerosis (MS), ${ }^{51}$ or AQP4-specific Teff cells, ${ }^{41}$ might initiate CNS inflammation, which in AQP4-seropositive NMOSD is characterized by accumulation of neutrophils (Neutro.) and eosinophils (Eosin.). ${ }^{22}$ Lymphocytes (Lymph.), which are characteristic in MS ${ }^{25}$ and MOG-induced EAE lesions, ${ }^{29,52}$ are shown in MOG Ig+-associated inflammation, although their presence has not been confirmed. In both conditions, inflammation may disrupt integrity of the blood-brain barrier, permitting entry of antibodies. ${ }^{37,39,40} \mathrm{MOG}$-specific antibodies presumably bind MOG expressed on myelin-forming oligodendrocytes and myelin, a layer that surrounds the axons extending from neuron $(\mathrm{N})$ cell bodies. While the precise contribution of MOG-specific antibodies to MOG $\mathrm{Ig}^{+}$opticospinal inflammation is yet unknown, MOG-specific antibodies promote demyelination in $\mathrm{EAE}^{37}$ and have been identified in MS lesions. ${ }^{24}$ Damage to oligodendrocytes or myelin may be associated with release of myelin basic protein (MBP). ${ }^{46}$ AQP4-specific IgG1 binds to AQP4 water channels, which are abundant on astrocyte end-feet processes. AQP4-specific IgG1 fixes complement, which amplifies astrocyte injury. Glial fibrillary acidic protein (GFAP) may be released upon injury to astrocytes. ${ }^{46,47}$ AQP4targeted damage of NMOSD is associated with relative preservation of myelin. ${ }^{22}$ Copyright XavierStudio, reprinted with permission.

Nonetheless, certain immunologic features of NMO are shared with this novel MOG Ig-associated opticospinal inflammatory disease. Whereas oligoclonal IgG bands (OBs) are identified in the CSF of most patients with MS, they are detected in only a minority of patients with $\mathrm{NMO} .{ }^{33}$ As in $\mathrm{NMO}$, OBs were rarely detected in patients with MOG Igassociated opticospinal inflammatory disease. ${ }^{3}$
It is recognized that NMO $\operatorname{IgG}$ is mostly produced outside the CNS, as studies have demonstrated that its concentration in serum is many times higher than in CSF. ${ }^{34}$ Thus, both the identification of MOG-specific antibodies in the serum and the relative absence of CSF OBs suggest that, like in NMO, the MOGspecific humoral immune process occurs predominantly outside the CNS in these patients. 
Of interest, histologic analysis of NMO lesions in experimental animal studies suggests that the unique cellular composition of $\mathrm{NMO}$ lesions may reflect the complement-fixing properties of NMO IgG, an IgG1 subtype. ${ }^{35}$ While presumably targeting oligodendrocytes and not astrocytes, one could imagine that serum-derived MOG-specific Ig, whose isotype has yet to be characterized, could promote accumulation of cell types typically detected in NMO in AQP4-seronegative patients. Then again, this possibility seems unlikely because it is well-known that transfer of MOG-specific antibodies in several MOGinduced EAE models in different species promotes demyelinating lesions that resemble MS. ${ }^{24,36-38}$ Also, systemic administration of MOG-specific antibodies alone, like NMO IgG or AQP4-specific antibodies, is not considered pathogenic in the absence of CNS cellular inflammation. ${ }^{37,39,40}$ AQP4-specific T cells are detected in AQP4-seropositive NMO patients $^{41,42}$ and exhibit Th17 polarization. ${ }^{41}$ It has been observed that Th17-polarized myelin protein-specific $T$ cells expanded in vitro can induce atypical or opticospinal forms of EAE that are associated with CNS recruitment of neutrophils, ${ }^{43-45}$ so it is conceivable that MOG-specific T cells, which likely direct the peripheral humoral anti-MOG antibody response (see the figure), could promote CNS accumulation of neutrophils in MOG $\mathrm{Ig}^{+}$ AQP4-seronegative patients. Regardless, without pathologic examination of affected CNS tissue from MOG $\mathrm{Ig}^{+} \mathrm{AQP} 4$-seronegative patients, such views are only speculative.

If this opticospinal inflammatory disorder associated with MOG-specific Ig is an NMOSD, one should recognize that it represents just one subset of AQP4-seronegative NMOSD. ${ }^{3,4}$ Although the sample sizes were small, in 1 of the 3 reports, antibody tests to MOG or AQP4 were repeated after recovery from the acute exacerbation in patients who had previously demonstrated antibodies to MOG or AQP4, respectively. ${ }^{3}$ Of interest, they could no longer detect MOG-specific antibodies in more than $50 \%$ of the original MOG $\mathrm{Ig}^{+}$ patients or AQP4-specific antibodies in 15\% of the patients who initially had detectable antibodies to AQP4. Thus, MOG Ig seropositivity may not be a stable serologic phenotype. One might therefore question whether generation of MOG-specific antibodies in these individuals could also reflect "acute phase" collateral injury to oligodendrocytes, innocent bystanders from an immune attack primarily targeting astrocytes. Consequently, the MOG-specific antibodies in NMOSD might represent an example of both "intercellular" and "intermolecular" epitope spreading. Yet if response to oligodendrocytes occurs secondarily, one would anticipate detection of both AQP4-specific and MOG-specific antibodies simultaneously in some patients. However, when antibodies to AQP4 or MOG were present, they were detected to only 1 of these 2 CNS autoantigens in nearly all of the patients described. Further, in a recent case report ${ }^{46}$ of a patient who experienced a severe exacerbation and also fulfilled diagnostic criteria for NMO but was AQP4-seronegative, serum anti-MOG antibodies corresponded to an elevation in CSF myelin basic protein (MBP), indicative of acute injury to myelin. However, there was no elevation in CSF glial fibrillary acidic protein (GFAP), a marker of astrocyte damage that is elevated during exacerbations in AQP4-seropositive NMO patients. ${ }^{47}$ Clinical improvement in this patient was associated with reduction in both serum levels of antiMOG antibodies and CSF MBP. Clearly, more longitudinal studies evaluating antiMOG antibodies, as well as surrogate markers of myelin or astrocyte damage (e.g., CSF MBP and GFAP, respectively), should be conducted in both AQP4-seronegative and AQP4-seropositive patients.

Identification of this unique MOG $\mathrm{Ig}^{+}$ phenotype of opticospinal inflammatory disease creates an additional variable to consider when conducting clinical treatment trials in NMOSD. Clinical investigators are already familiar with heterogeneity, as approximately one-fourth of the patients diagnosed with NMOSD are AQP4-seronegative. ${ }^{1}$ Because the natural history of $\mathrm{MOG} \mathrm{Ig}^{+}$patients is distinct and recovery without relapse could be the norm, including all AQP4-seronegative NMOSD patients together without consideration of MOG antibody status could compromise the capability of detecting a true benefit of a candidate therapeutic. However, because 
NMO is a rare condition and there are currently no approved therapies, there may be a desire to include such patients in clinical treatment trials. Thus, when designing NMO clinical trials, it would be advantageous to consider these subgroups when calculating sample sizes for adequate statistical power and to plan prospectively to analyze data obtained from them separately.

Identifying a problem is easier than solving it. The criteria for diagnosing MS and classifying its subtypes have been refined and improved with multiple iterations. ${ }^{48}$ Similarly, criteria for diagnosing NMO have certainly advanced in the 10 years since the discovery of NMO IgG. ${ }^{21}$ As our understanding of the pathogenic mechanisms of NMO increases, one can anticipate further refinements in its diagnostic criteria. However, the term MOG $\mathrm{Ig}^{+} \mathrm{AQP} 4-$ seronegative NMOSD represents a fundamental disconnect with our current understanding of NMO as an astrocytopathy. Thus, one should exercise caution in applying the term NMOSD to MOG $\mathrm{IgG}^{+}$patients. While one may consider categorization according to antigen specificity, e.g., AQP4 autoimmunity ("aquaporinopathy") and MOG autoimmunity ("MOG-opathy"), this may not accurately reflect the AQP4-seronegative astrocytopathy, currently classified as NMOSD. Because the majority of NMOSD is AQP4-seropositive and a minority of AQP4-seronegative NMOSD is $\mathrm{MOG} \mathrm{Ig}^{+}$, pathologic examination of sufficient numbers of AQP4-seronegative, MOG Ig-seronegative NMOSD cases is particularly important. Ultimately, neuropathologic examination of several AQP4-seronegative and MOG $\mathrm{Ig}^{+}$cases may dictate whether opticospinal inflammatory disease associated with MOGspecific antibodies is classified as a member of NMOSD, as opticospinal MS, or as a unique condition. In our view, until that time, the MOG $\mathrm{Ig}^{+}$opticospinal phenotype should be separated from NMOSD.

\section{AUTHOR CONTRIBUTIONS}

Scott S. Zamvil: drafting/revising manuscript, study concept or design, analysis or interpretation of data. Anthony J. Slavin: drafting/revising the manuscript.

\section{ACKNOWLEDGMENT}

The authors thank Drs. Wolfgang Brück, Klaus Lehmann-Horn, Patricia Nelson, and Michel Varrin-Doyer for helpful discussions and review of the manuscript.

\section{STUDY FUNDING}

No targeted funding reported.

\section{DISCLOSURE}

S.S. Zamvil has received honoraria for serving on data safety monitoring boards for MS trials conducted by BioMS, Teva Pharmaceuticals, Inc., and Eli Lilly and Co.; is deputy editor for Neurology: Neuroimmunology $\&$ Neuroinflammation; is an associate editor for Journal of the Neurological Sciences; holds a patent for aquaporin- 4 peptides and methods for using same; received honoraria from Biogen-Idec, Teva Neuroscience, and Genzyme; has consulted for Biogen-Idec, Teva Neuroscience, and Genzyme; is on the speakers' bureau for Advanced Health Media and Biogen; and has received research support from NIH, NMSS, Guthy Jackson Charitable Foundation, and Maisin Foundation. A.J. Slavin is an employee of Abbvie Bioresearch Center and was formerly an employee of Boehringer Ingelheim Pharmaceuticals. Go to Neurology.org/nn for full disclosures.

Received October 24, 2014. Accepted in final form December 1, 2014.

\section{REFERENCES}

1. Jarius S, Wildemann B. AQP4 antibodies in neuromyelitis optica: diagnostic and pathogenetic relevance. Nat Rev Neurol 2010;6:383-392.

2. Pittock SJ, Lennon VA, de Seze J, et al. Neuromyelitis optica and non organ-specific autoimmunity. Arch Neurol 2008;65:78-83.

3. Kitley J, Waters P, Woodhall M, et al. Neuromyelitis optica spectrum disorders with aquaporin- 4 and myelinoligodendrocyte glycoprotein antibodies: a comparative study. JAMA Neurol 2014;71:276-283.

4. Sato DK, Callegaro D, Lana-Peixoto MA, et al. Distinction between MOG antibody-positive and AQP4 antibody-positive NMO spectrum disorders. Neurology 2014;82:474-481.

5. Mader S, Gredler V, Schanda K, et al. Complement activating antibodies to myelin oligodendrocyte glycoprotein in neuromyelitis optica and related disorders. J Neuroinflammation 2011;8:184.

6. Kitley J, Woodhall M, Waters P, et al. Myelin-oligodendrocyte glycoprotein antibodies in adults with a neuromyelitis optica phenotype. Neurology 2012;79:1273-1277.

7. Rostasy K, Mader S, Hennes EM, et al. Persisting myelin oligodendrocyte glycoprotein antibodies in aquaporin-4 antibody negative pediatric neuromyelitis optica. Mult Scler 2013;19:1052-1059.

8. Höftberger R, Sepulveda M, Armangue T, et al. Antibodies to MOG and AQP4 in adults with neuromyelitis optica and suspected limited forms of the disease. Mult Scler Epub 2014 Oct 24.

9. Shimizu Y, Yokoyama K, Misu T, et al. Development of extensive brain lesions following interferon beta therapy in relapsing neuromyelitis optica and longitudinally extensive myelitis. J Neurol 2008;255:305-307.

10. Palace J, Leite MI, Nairne A, Vincent A. Interferon Beta treatment in neuromyelitis optica: increase in relapses and aquaporin 4 antibody titers. Arch Neurol 2010;67: 1016-1017.

11. Barnett MH, Prineas JW, Buckland ME, Parratt JD, Pollard JD. Massive astrocyte destruction in neuromyelitis optica despite natalizumab therapy. Mult Scler 2012;18: 108-112.

12. Kitley J, Evangelou N, Kuker W, Jacob A, Leite MI, Palace J. Catastrophic brain relapse in seronegative 
NMO after a single dose of natalizumab. J Neurol Sci 2014;339:223-225.

13. O'Connor KC, McLaughlin KA, De Jager PL, et al. Selfantigen tetramers discriminate between myelin autoantibodies to native or denatured protein. Nat Med 2007;13: 211-217.

14. McLaughlin KA, Chitnis T, Newcombe J, et al. Agedependent B cell autoimmunity to a myelin surface antigen in pediatric multiple sclerosis. J Immunol 2009;183: 4067-4076.

15. Brilot F, Dale RC, Selter RC, et al. Antibodies to native myelin oligodendrocyte glycoprotein in children with inflammatory demyelinating central nervous system disease. Ann Neurol 2009;66:833-842.

16. Probstel AK, Dornmair K, Bittner R, et al. Antibodies to MOG are transient in childhood acute disseminated encephalomyelitis. Neurology 2011;77:580-588.

17. Di Pauli F, Mader S, Rostasy K, et al. Temporal dynamics of anti-MOG antibodies in CNS demyelinating diseases. Clin Immunol 2011;138:247-254.

18. Huppke P, Rostasy K, Karenfort M, et al. Acute disseminated encephalomyelitis followed by recurrent or monophasic optic neuritis in pediatric patients. Mult Scler 2013; 19:941-946.

19. Baumann M, Sahin K, Lechner C, et al. Clinical and neuroradiological differences of paediatric acute disseminating encephalomyelitis with and without antibodies to the myelin oligodendrocyte glycoprotein. J Neurol Neurosurg Psychiatry Epub 2014 Aug 13.

20. Lennon VA, Wingerchuk DM, Kryzer TJ, et al. A serum autoantibody marker of neuromyelitis optica: distinction from multiple sclerosis. Lancet 2004;364:2106-2112.

21. Wingerchuk DM, Lennon VA, Pittock SJ, Lucchinetti CF, Weinshenker BG. Revised diagnostic criteria for neuromyelitis optica. Neurology 2006;66:1485-1489.

22. Lucchinetti CF, Guo Y, Popescu BF, Fujihara K, Itoyama $\mathrm{Y}$, Misu T. The pathology of an autoimmune astrocytopathy: lessons learned from neuromyelitis optica. Brain Pathol 2014;24:83-97.

23. Lucchinetti C, Bruck W, Parisi J, Scheithauer B, Rodriguez M, Lassmann H. Heterogeneity of multiple sclerosis lesions: implications for the pathogenesis of demyelination. Ann Neurol 2000;47:707-717.

24. Genain CP, Cannella B, Hauser SL, Raine CS. Identification of autoantibodies associated with myelin damage in multiple sclerosis. Nat Med 1999;5:170-175.

25. Lassmann H, Bruck W, Lucchinetti CF. The immunopathology of multiple sclerosis: an overview. Brain Pathol 2007;17:210-218.

26. Bettelli E, Pagany M, Weiner HL, Linington C, Sobel RA, Kuchroo VK. Myelin oligodendrocyte glycoproteinspecific $\mathrm{T}$ cell receptor transgenic mice develop spontaneous autoimmune optic neuritis. J Exp Med 2003;197: 1073-1081.

27. Krishnamoorthy G, Lassmann H, Wekerle H, Holz A. Spontaneous opticospinal encephalomyelitis in a doubletransgenic mouse model of autoimmune $\mathrm{T}$ cell/B cell cooperation. J Clin Invest 2006;116:2385-2392.

28. Bettelli E, Baeten D, Jager A, Sobel RA, Kuchroo VK. Myelin oligodendrocyte glycoprotein-specific $\mathrm{T}$ and $\mathrm{B}$ cells cooperate to induce a Devic-like disease in mice. J Clin Invest 2006;116:2393-2402.

29. Molnarfi N, Schulze-Topphoff U, Weber MS, et al. MHC class II-dependent B cell APC function is required for induction of CNS autoimmunity independent of myelin-specific antibodies. J Exp Med 2013;210: 2921-2937.

30. Brum DG, Barreira AA, dos Santos AC, et al. HLA-DRB association in neuromyelitis optica is different from that observed in multiple sclerosis. Mult Scler 2010;16:21-29.

31. Lutterotti A, Reindl M, Gassner C, et al. Antibody response to myelin oligodendrocyte glycoprotein and myelin basic protein depend on familial background and are partially associated with human leukocyte antigen alleles in multiplex families and sporadic multiple sclerosis. J Neuroimmunol 2002;131:201-207.

32. Dale RC, Tantsis EM, Merheb V, et al. Antibodies to MOG have a demyelination phenotype and affect oligodendrocyte cytoskeleton. Neurol Neuroimmunol Neuroinflamm 2014;1:e12. doi: 10.1212/NXI. 0000000000000012.

33. Jarius S, Paul F, Franciotta D, et al. Cerebrospinal fluid findings in aquaporin- 4 antibody positive neuromyelitis optica: results from 211 lumbar punctures. J Neurol Sci 2011;306:82-90.

34. Jarius S, Franciotta D, Paul F, et al. Cerebrospinal fluid antibodies to aquaporin- 4 in neuromyelitis optica and related disorders: frequency, origin, and diagnostic relevance. J Neuroinflammation 2010;7:52.

35. Saadoun S, Waters P, MacDonald C, et al. Neutrophil protease inhibition reduces neuromyelitis optica-immunoglobulin G-induced damage in mouse brain. Ann Neurol 2012;71: 323-333.

36. Linington C, Bradl M, Lassmann H, Brunner C, Vass K. Augmentation of demyelination in rat acute allergic encephalomyelitis by circulating mouse monoclonal antibodies directed against a myelin/oligodendrocyte glycoprotein. Am J Pathol 1988;130:443-454.

37. Litzenburger T, Fassler R, Bauer J, et al. B lymphocytes producing demyelinating autoantibodies: development and function in gene-targeted transgenic mice. J Exp Med 1998;188:169-180.

38. Saadoun S, Waters P, Owens GP, Bennett JL, Vincent A, Papadopoulos MC. Neuromyelitis optica MOG-IgG causes reversible lesions in mouse brain. Acta Neuropathol Commun 2014;2:35.

39. Bradl M, Misu T, Takahashi T, et al. Neuromyelitis optica: pathogenicity of patient immunoglobulin in vivo. Ann Neurol 2009;66:630-643.

40. Bennett JL, Lam C, Kalluri SR, et al. Intrathecal pathogenic anti-aquaporin- 4 antibodies in early neuromyelitis optica. Ann Neurol 2009;66:617-629.

41. Varrin-Doyer M, Spencer CM, Schulze-Topphoff U, et al. Aquaporin 4-specific $\mathrm{T}$ cells in neuromyelitis optica exhibit a Th17 bias and recognize Clostridium ABC transporter. Ann Neurol 2012;72:53-64.

42. Vaknin-Dembinsky A, Brill L, Kassis I, et al. T-cell reactivity against AQP4 in neuromyelitis optica. Neurology 2012;79:945-946.

43. Stromnes IM, Cerretti LM, Liggitt D, Harris RA, Goverman JM. Differential regulation of central nervous system autoimmunity by $\mathrm{T}(\mathrm{H}) 1$ and $\mathrm{T}(\mathrm{H}) 17$ cells. Nat Med 2008;14:337-342.

44. Kroenke MA, Carlson TJ, Andjelkovic AV, Segal BM. IL12- and IL-23-modulated T cells induce distinct types of EAE based on histology, CNS chemokine profile, and response to cytokine inhibition. J Exp Med 2008;205: $1535-1541$. 
45. Herges K, de Jong BA, Kolkowitz I, et al. Protective effect of an elastase inhibitor in a neuromyelitis optica-like disease driven by a peptide of myelin oligodendroglial glycoprotein. Mult Scler 2012;18:398-408.

46. Ikeda K, Kiyota N, Kuroda H, et al. Severe demyelination but no astrocytopathy in clinically definite neuromyelitis optica with anti-myelin-oligodendrocyte glycoprotein antibody. Mult Scler Epub 2014 Sep 25.

47. Takano R, Misu T, Takahashi T, Sato S, Fujihara K, Itoyama Y. Astrocytic damage is far more severe than demyelination in NMO: a clinical CSF biomarker study. Neurology 2010;75:208-216.

48. Polman CH, Reingold SC, Banwell B, et al. Diagnostic criteria for multiple sclerosis: 2010 revisions to the McDonald criteria. Ann Neurol 2011;69:292-302.
49. Crotty S. Follicular helper CD4 T cells (TFH). Annu Rev Immunol 2011;29:621-663.

50. Shetty A, Gupta SG, Varrin-Doyer M, et al. Immunodominant T-cell epitopes of MOG reside in its transmembrane and cytoplasmic domains in EAE. Neurol Neuroimmunol Neuroinflamm 2014;1:e22. doi: 10. 1212/NXI.0000000000000022.

51. Varrin-Doyer M, Shetty A, Spencer CM, et al. MOG transmembrane and cytoplasmic domains contain highly stimulatory T-cell epitopes in MS. Neurol Neuroimmunol Neuroinflamm 2014;1:e20. doi: 10.1212/NXI.0000000000000020.

52. Slavin AJ, Soos JM, Stuve O, et al. Requirement for endocytic antigen processing and influence of invariant chain and $\mathrm{H}-2 \mathrm{M}$ deficiencies in CNS autoimmunity. J Clin Invest 2001;108:1133-1139. 


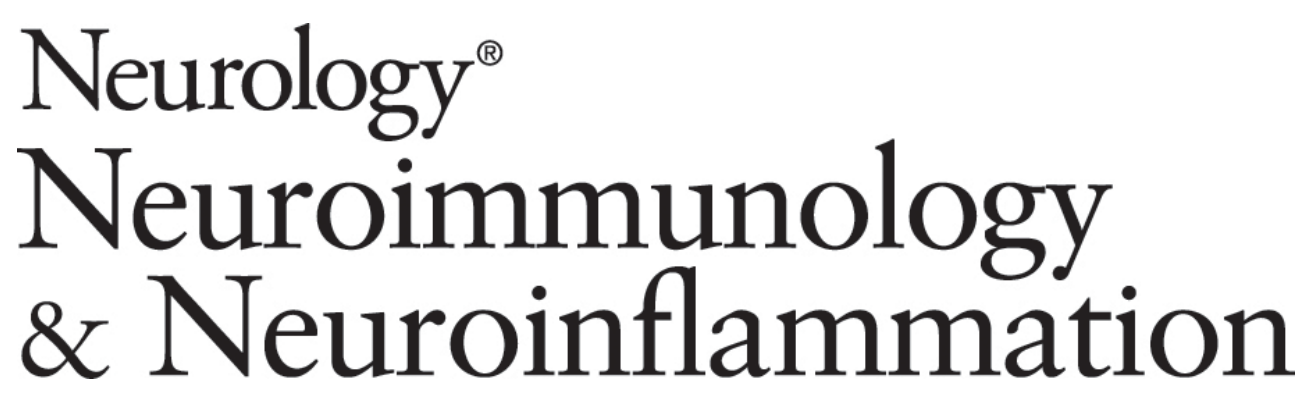

Does MOG Ig-positive AQP4-seronegative opticospinal inflammatory disease justify a diagnosis of NMO spectrum disorder?

Scott S. Zamvil and Anthony J. Slavin

Neurol Neuroimmunol Neuroinflamm 2015;2;

DOI 10.1212/NXI.0000000000000062

This information is current as of January 22, 2015

Neurol Neuroimmunol Neuroinflamm is an official journal of the American Academy of Neurology.

Published since April 2014, it is an open-access, online-only, continuous publication journal. Copyright $\odot$ 2015 American Academy of Neurology. All rights reserved. Online ISSN: 2332-7812.

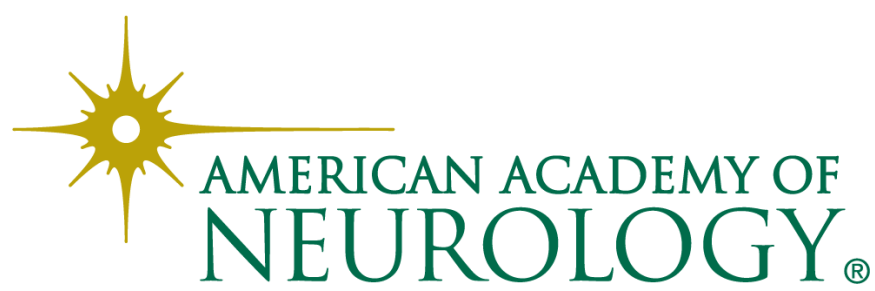




\section{Updated Information \& Services}

References

Citations

Subspecialty Collections

Permissions \& Licensing

Reprints including high resolution figures, can be found at: http://nn.neurology.org/content/2/1/e62.full.html

This article cites 49 articles, 5 of which you can access for free at: http://nn.neurology.org/content/2/1/e62.full.html\#\#ref-list-1

This article has been cited by 9 HighWire-hosted articles: http://nn.neurology.org/content/2/1/e62.full.html\#\#otherarticles

This article, along with others on similar topics, appears in the following collection(s):

All Clinical Neurology

http://nn.neurology.org//cgi/collection/all_clinical_neurology All Immunology

http://nn.neurology.org//cgi/collection/all_immunology

Autoimmune diseases

http://nn.neurology.org//cgi/collection/autoimmune_diseases

Devic's syndrome

http://nn.neurology.org//cgi/collection/devics_syndrome

Multiple sclerosis

http://nn.neurology.org//cgi/collection/multiple_sclerosis

Information about reproducing this article in parts (figures,tables) or in its entirety can be found online at:

http://nn.neurology.org/misc/about.xhtml\#permissions

Information about ordering reprints can be found online: http://nn.neurology.org/misc/addir.xhtml\#reprintsus

Neurol Neuroimmunol Neuroinflamm is an official journal of the American Academy of Neurology.

Published since April 2014, it is an open-access, online-only, continuous publication journal. Copyright $\odot$ 2015 American Academy of Neurology. All rights reserved. Online ISSN: 2332-7812.

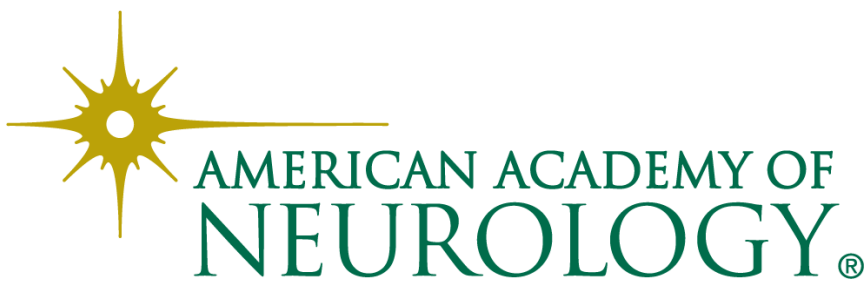

